\section{Creep of Natural Rubber Vulcanizates filled with Carbon Black}

HARWOOD et al. have recently shown ${ }^{1,2}$ that the phenomenon of stress softening in vulcanized natural rubber containing carbon black as a filler is chiefly associated with changes taking place in the polymer phase--and not, as had previously been supposed, with breakdown of polymer-filler, or filler-filler interactions.

In this communication the changes in creep behaviour brought about by pre-stressing a filled rubber (a conventional $N$-cyclohexyl benzthiazyl sulphenamide accelerated sulphur vulcanizate containing forty parts by weight of lamp carbon black per hundred parts of rubber) are briefly described. The results indicate that, as with stress softening, the principal effect of pre-stressing is a change in the polymer phase, although there are indications that some breakdown associated with the filler does take place.

It is known to industry, presumably empirically, that pre-stressing of either rubber or metal springs improves the subsequent creep performance. The creep rate, in tension under constant load, was measured at various extensions for both new and pre-stressed test pieces. The rate can be defined as the percentage increase in extension per decade of time, because this increase is essentially proportional to the logarithm of the time under load. This increase is expressed as a percentage of the "initial" extension, which is arbitrarily taken as that measured 1 min after loading.

The test piece was pre-stressed for $l$ h at 100 per cent extension, and allowed to recover for at least $24 \mathrm{~h}$ before the croep test. This moderate pre-stressing procedure results in less than 1 per cent permanent set and only about 7 per cent decrease in modulus.

The results of the creep tests are given in Fig. 1; they show that the creep rate is lower for the pre-stressed material and that there is a marked minimum at the pre-stress limit.

The decrease in crcep rate subsequent to pre-stressing could be associated either with polymer-filler or fillerfiller breakdown, or with changes in the gum matrix. If the latter is the case then the same phenomenon of decreasing creep rate after pre-stressing should also be observable in a pure gum rubber- that is, a rubber containing no filler particles. For fair comparison with the results of Fig. 1, the pre-stress on the gurn rubber should be the same as that on the filled rubber. As a result of strain amplification ${ }^{3}$, this means that the equivalent gum

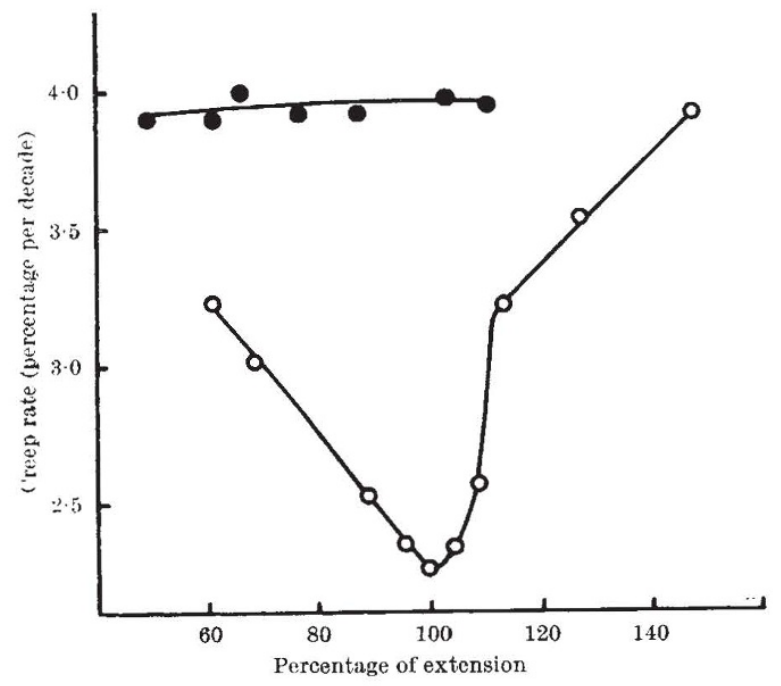

Fig. 1. The variation of creep rate with extension for new test pieces (O) and pre-stressed test pieces $(O)$ of natural rubber filled with lampblack.
The pre-stress of $20 \mathrm{~kg} \mathrm{~cm}^{-2}$ corresponds to about 100 per cent extension.

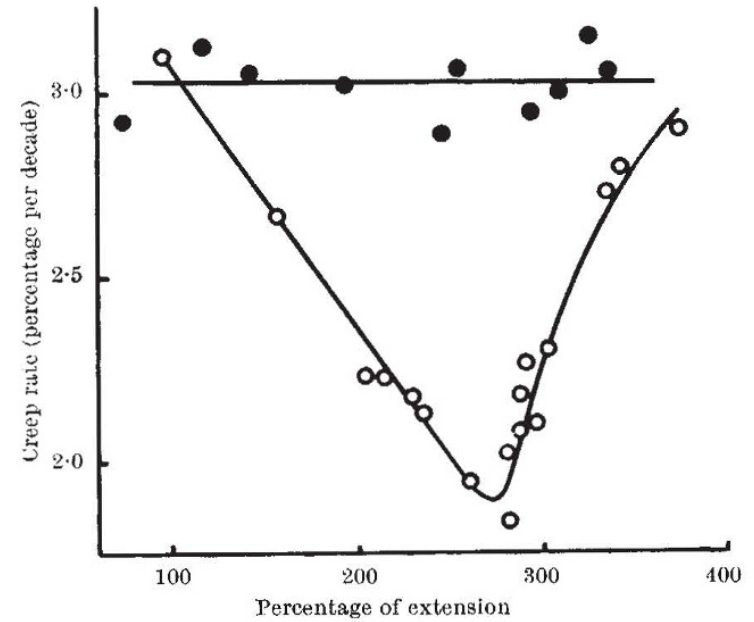

Fig. 2. The variation of creep rate with extension for new test pieces ( $)$ and pre-stressed test pieces ( $O$ ) of gum (unfilled) natural rubber. The pre-stress of $20 \mathrm{~kg} \mathrm{~cm}^{-2}$ corresponds to about 300 per cent extension.

experiments are carried out at considerably higher extensions. The results are shown in Fig. 2. Qualitatively the effect is obviously very similar to that in the filled rubbersimply being scaled down to lower overall rates. Quantitative comparison suggests that changes in the polymer phase of the filled rubber can account for most, but not all, of the effect of pre-stressing. The filler probably does contribute an additional, but smaller, relaxation mechanism.

We suggest that most of the creep is the result of the time dopendent rupture of "temporary" crosslinks. These crosslinks are probably associated with weak secondary forces rather than with primary bonds. It may be that they aro broken down rather rapidly and essentially irreversibly by the mechanical pre-stress. This means that the network is now nearer to its equilibrium configuration and in subsequent tests a lower creep rate will be observed. 'This idea is consistent with the slight softening which is observed for the pre-stressed rubber.

C. J. Derham

A. G. Thomas

Natural Rubber Producers' Rescarch Association,

Welwyn Garden City,

Hertfordshire.

Received February 5; revised February 29, 1968.

Harwood, J. A. C., Mullins, T., and Payne, A. R., J. Appl. Polymer Sci., 9 , 3011 (1965).

Harwood, J. A. C., Mullins, I., and Payne, A. R., J. Inst. Rubber Indust., 1, 1 (1.967).

${ }^{3}$ Mullins, L., and Tobin, X. R., Proc. Third Rubber Techn. Conf., Tondon. $397(1954)$.

\section{THE SOLID STATE}

\section{Crystal Structure of Sapphirine}

SAPPHIRINE is a principal constituent of certain high grade silica-deficient metamorphic rocks at Fiskenaesset, West Greenland, where it occurs with cordierite, corundum, anorthite and biotite. A crystallo-chemical enigma, it is one of the few rock-forming minerals with unknown crystal structure.

A fine specimen was donated by Dr Brian Windley, who collected the sample at the typo locality near Fis. kenaesset harbour. A nearly equant fragment of $0.3 \mathrm{~mm}$ mean dimension was selected for three-dimensional crystal structure analysis. Six thousand independent reflexions were collected on 'Pailred', an automatic diffractometer, using monochromatized $\mathrm{MoK} K_{\alpha}$ radiation. Of these, 3,600 were non-zero and 2,000 "low-angle" reflexions were used for the ensuing structure analysis. 